\title{
Performance comparison of varistor models under high current derivative impulses
}

\author{
Mahesh Edirisinghe ${ }^{1}$, Raul Montaño ${ }^{2}$, Vernon Cooray ${ }^{2}$, F. Roman ${ }^{3}$ \\ ${ }^{1}$ Department of Physics, Faculty of Science, University of Colombo, Colombo 03, Sri Lanka \\ ${ }^{2}$ Division of Electricity, Uppsala University, SE-751 05 Uppsala, Sweden, \\ ${ }^{3}$ Universidad Nacional de Colombia, Bogota, Colombia \\ E-mail address: mahesh@phys.cmb.ac.lk
}

\begin{abstract}
Surge protective devices (SPD) testing procedures are mainly performed with standard current pulse types. However, none of these standard current waveforms reproduce the very fast rise time and the large peak current derivatives observed in subsequent return strokes. In the literature there are several mathematical models to represent metal oxide varistor that have been developed based on standard impulse conditions. These models are being used routinely in the analysis of the various electronic circuits under transient conditions. In this paper, a study was conducted to have a performance comparison between the two varistor models, simplified varistor model and Durbak's model, available in the literature under high current derivative impulses. The experiments and simulations were performed on disk type varistors with different diameter sizes, i.e., $20 \mathrm{~mm}, 10 \mathrm{~mm}$, and $05 \mathrm{~mm}$ with nominal operating voltage of $230 \mathrm{~V}$. The Roman Generator developed at Uppsala University was used as the high current derivative impulse generator which can produce a peak current up to $1500 \mathrm{~A}$ with $10 \mathrm{~ns}$ rise time and its rate-of-rise is in the order of $1011 \mathrm{~A} / \mathrm{s}$. The results showed that for standard $8 / 20 \mu$ s lightning impulses, simulation results of these models had a good agreement with the experimental data. However, these two models need to be improving in order to improve their performance under high current derivative impulses into the sub-microsecond range.
\end{abstract}

Keywords: Varistors; Fast front current impulses

\section{INTRODUCTION}

Varistor is one of a most used device in protection system against transients. Its fast response makes it suitable for surge suppression, providing a high protection level to the load. Nowadays several software are available to evaluate the performances of electrical systems under transient conditions that allow engineers to design the over-voltage protection properly. Hence, it is necessary to have accurate models that can be implemented in these simulations during the design process of the over-voltage protection system. This will optimize the design of the insulation coordination of the system under study.

Moreover, several studies have been conducted to determine the response of varistors under different transient conditions [1-4]. However, the majority of the experiments reported in the literature have been performed for high voltage varistors and only a few studies have been conducted for low voltage varistors [5-9]. In the case of simulations, varistor models 
available in the literature $[10,11]$ have been developed for standard current waveforms, without taking into account responsive behavior under high current derivative impulses.

It is well known facts that, the maximum current derivative of a lightning flash could be in the order of $100 \mathrm{kA} / \mu \mathrm{s}$ as indicated in [5,6]. For this reason, it can be expected that the performance of the varistors under a threat from real lightning threat conditions may differ considerably from their behavior under standard current impulse waveforms. This was confirmed experimentally by the authors of this study as explained in $[5,6]$ by injecting fast current impulses having peak current derivatives in the order of $120 \mathrm{kA} / \mu \mathrm{s}$. In this paper, a study was conducted to have a performance comparison between the two varistor models, simplified varistor model and Durbak's model, available in the literature [10,11] under high current derivative impulses. The results were compared with experimental data for standard wave shapes as well as for fast front current impulses with same data as explained in $[5,6]$.

\section{EXPERIMENTAL SETUP}

The experiments and simulations were performed on disk type varistors with different diameter sizes, i.e., $20 \mathrm{~mm}, 10 \mathrm{~mm}$, and $05 \mathrm{~mm}$ with nominal operating voltage of $230 \mathrm{~V}$ (S05K230, S10K230 \& S20K230).

The "Fast Transient Generator" or "Roman Generator", developed at Uppsala University by Roman [5,6,12-15] was used as a "High Current Derivative Impulse Generator". The generator can produce a peak current up to 1500 A with 10 ns rise time and its rate-of-rise is in the order of $1011 \mathrm{~A} / \mathrm{s}$ [5,6,12-15]. The shape of the current impulse is ring wave type which has the rapid rise to a peak value, followed by a damped oscillation with exponentially decaying amplitude. The voltage and current measurement system response was presented in $[5,6,15]$. The test sample was placed in a coaxial assembly necessary to observe the sub-microsecond pulse without test connections artifacts [16,17]. In Fig. 1 shows the recorded short circuit impulse current signature from the fast transient generator. A Schaffner generator NSG650 was used as the standard 8/20 $\mu$ s lightning impulse generator to inject standard $8 / 20 \mu$ s current waveform to the test sample as reported in $[5,6]$.

\section{METHODOLOGY}

In order to identify the parameters of each model, their response for a standard current waveform $(8 / 20 \mu \mathrm{s})$ was obtained. First, the obtained parameters and the model response with these parameters were compared with the experimental data. Then fast current impulses having peak current derivatives in the range of $120 \mathrm{kA} / \mu \mathrm{s}$ was applied to the above two varistor models and resulting voltage drop across its terminal was compared with the experimental data. The first model considered was the simplified varistor model [11] and the second one was the model presented by the IEEE working group in 1996 [11]. The later was originally presented by Daniel Durbak [10] and is highly recommended by the IEEE working group [11]. Therefore it is commonly referred as Durbak's Model. 

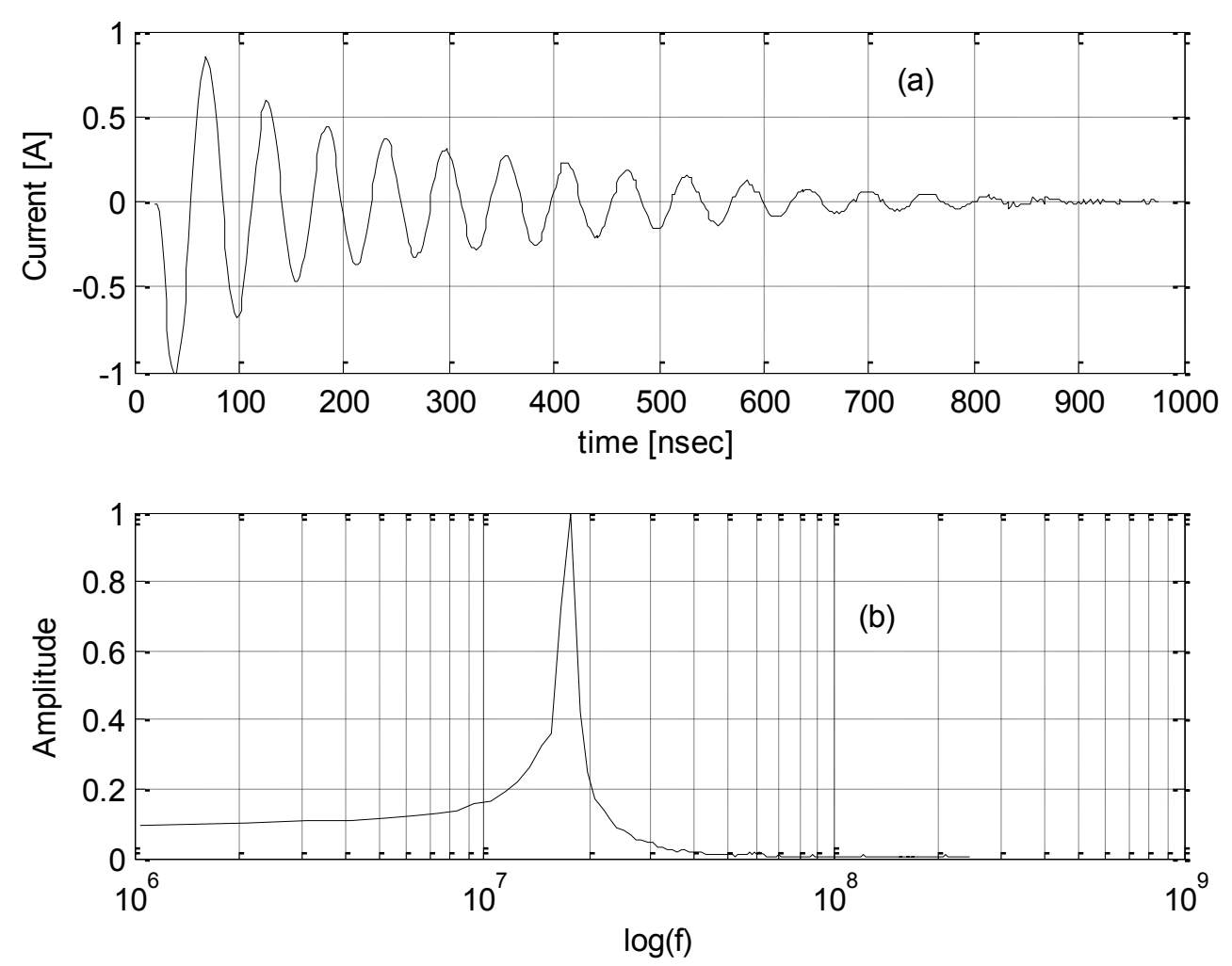

Fig. 1. (a) Fast current impulse produced by Roman Generator with a short circuit connected on its terminal (b) Normalized frequency spectrum [5].

\section{1. Simplified Varistor model}

As an electrical component, the simplest model available for a varistor was based on a combination of resistance, inductance and capacitance. The first two will represent the characteristics of the leads of the component while the last one, represents the properties of the material and the packaging process. All these three components will be connected with a variable resistor, which represent the non-linear characteristic of the varistor. The V-I characteristic for the non-linear branch can be written by the interpolation formula as given in equation 1 [18].

$$
\log (u)=b_{1}+b_{2} \cdot \log (i)+b_{3} \cdot e^{-\log (i)}+b_{4} \cdot e^{\log (i)}
$$

where,

$$
\begin{aligned}
& \mathrm{i}=\text { current flowing through the the varistor, } \\
& \mathrm{u}=\text { voltage across the varistor. }
\end{aligned}
$$

The parameters $b_{1}, b_{2}, b_{3} \& b_{4}$ are unique for each varistor type.

The circuit diagram of this model is shown in Fig. 2. For the present study, three different varistors with the same rated voltage were used. The parameters used for these components are from [18] and presented in Table 1, 


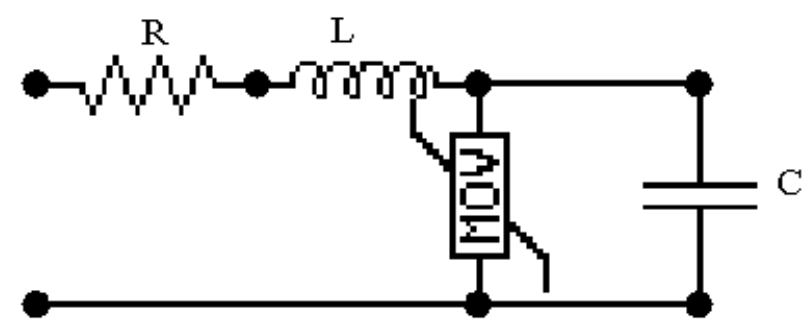

Fig. 2. Simplified varistor model.

Table 1. Parameters for simplified varistor model [18].

\begin{tabular}{|c|c|c|c|}
\hline \multirow{2}{*}{ Varistor Parameters } & \multicolumn{3}{|c|}{ Protective Component } \\
\cline { 2 - 4 } & S05K230 & S10K230 & S20K230 \\
\hline Capacitance (C) [pF] & 60 & 230 & 760 \\
\hline Inductance (L) $[\mathbf{n H}]$ & 8 & 12 & 13 \\
\hline $\mathbf{b}_{\mathbf{1}}$ & 2.6986925 & 2.6637804 & 2.6469709 \\
\hline $\mathbf{b}_{\mathbf{2}}$ & 0.0468290 & 0.0323975 & 0.0256509 \\
\hline $\mathbf{b}_{\mathbf{3}}$ & -0.0003190 & -0.0005318 & -0.0006073 \\
\hline $\mathbf{b}_{\mathbf{4}}$ & 0.0069771 & 0.0060573 & 0.0045643 \\
\hline
\end{tabular}

\section{2. Durbak's varistor model}

This model is the most used model in the literature for transient analysis of varistors. In this model, the component's non-linear characteristic is represented by two non-linear branches, $\mathrm{A}_{0}$ and $\mathrm{A}_{1}$, separated by an $\mathrm{R}, \mathrm{L}$ parallel combination that will have an important role for fast front signals. Its equivalent circuit diagram is shown in Fig. 3.

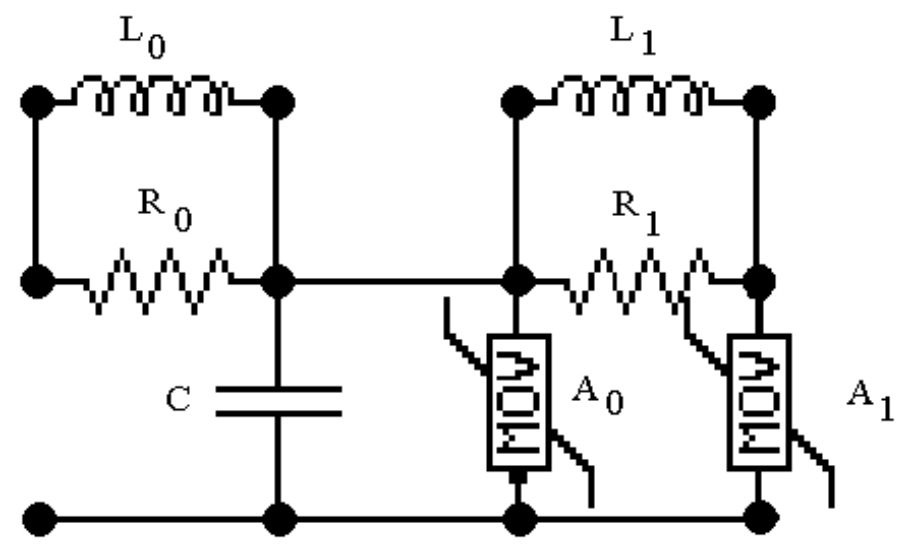

Fig. 3. Durbak's varistor model. 
As can be seen in Fig. 4, for high frequency components the inductance $L_{1}$ will limit the current flow through the non-linear branch $\mathrm{A}_{1}$ while for low frequencies these two non-linear branches will be in parallel. According to [4], the V-I characteristic of the two non-linear components can be determined by the ratio $\gamma=I_{o} / I_{1}$. This ratio $(\gamma)$ must be equal to 0.02 . Based on the assumption that $\gamma=0.02$, the V-I characteristics were determined as shown in Fig. 4. By combining these two branches, it is expected that the model could have a better performance at different frequency ranges.

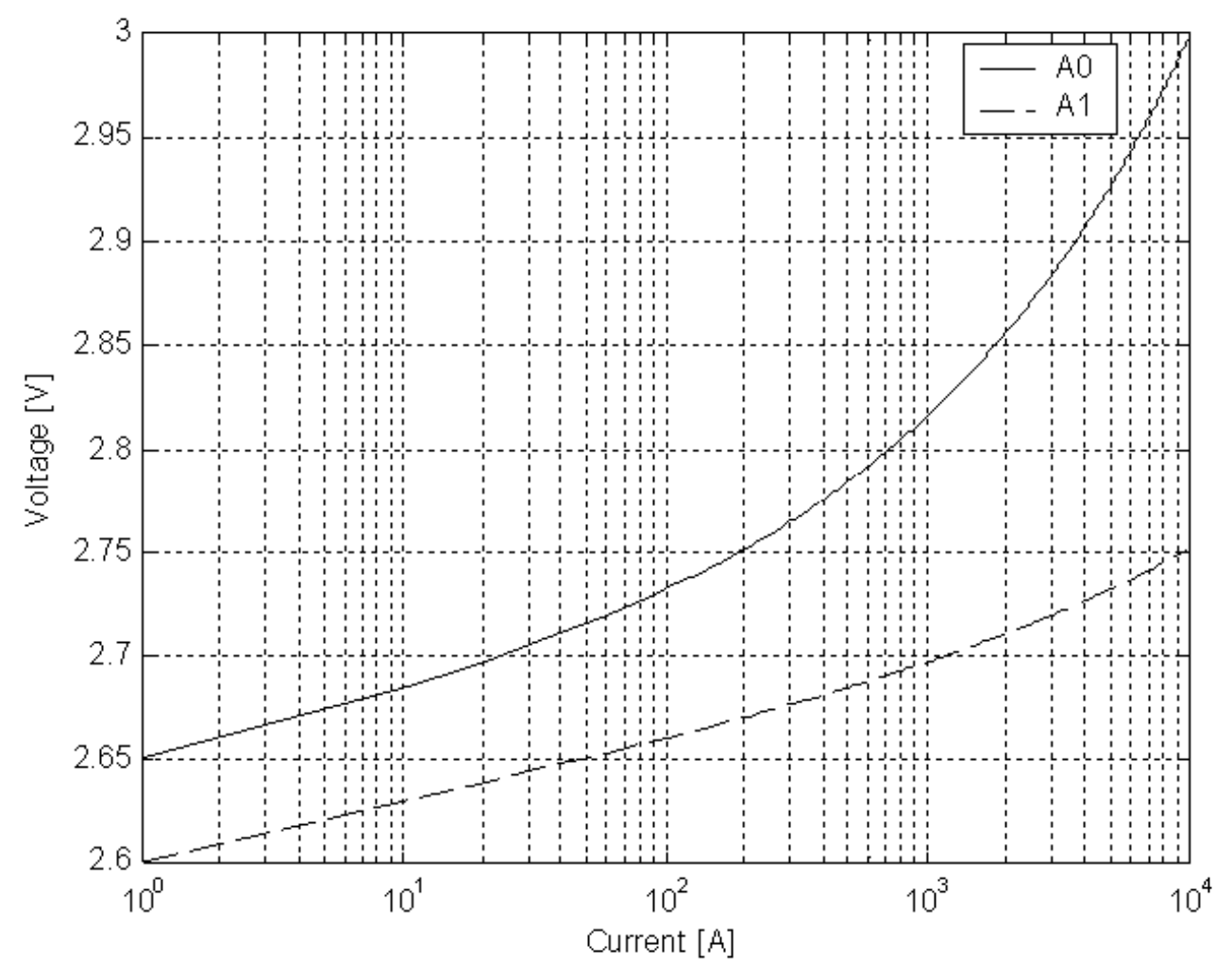

Fig. 4. V-I characteristic used on Durbak's varistor model. Continuous line: $A_{0}$, Dash line: $A_{1}$.

\section{SIMULATIONS RESULTS}

The two models selected for the present study were implemented into the Alternative Transients Program (ATP). The non-linear branches were simulated by using two varistor models and they were connected to the network via a variable resistor-type 94 in ATP.

\section{1. Response of varistor models to standard current impulse}

International standards (IEC 60-2, ANSI/IEEE Std 4-1978, and ANSI C62.1-1984) define $8 / 20 \mu$ s current waveform as a lightning current impulse [19]. A simple, approximate mathematical expression for $8 / 20 \mu$ s current waveform that is specified in IEC 60-2, ANSI/IEEE Std 4-1978, and ANSI C62.1-1984 is $I(t)$, as given by equation 2 [19].

$$
I(t)=A I_{P} t^{3} \exp (-t / \tau)
$$


where,

$\boldsymbol{t}$ is the time in $\mu \mathrm{s}(\mathrm{t} \geq 0)$,

$\boldsymbol{I}_{\boldsymbol{P}}$ is the peak value of the current,

$$
\boldsymbol{A}=0.01243(\mu \mathrm{s})^{-3} \text {, and } \tau=3.911 \mu \mathrm{s} \text {. }
$$

As it can be seen in Fig. 5, the current wave shape obtained from the equation 2 has a very good agreement with the experimental data. However, as it will be shown later, the experimental data has a low current tail after $35 \mu$ s that will result in a long voltage tail in the varistor response. This has been reported in [19], that equation 2 does not simulate the effects of continuing current in cloud to ground lightning.

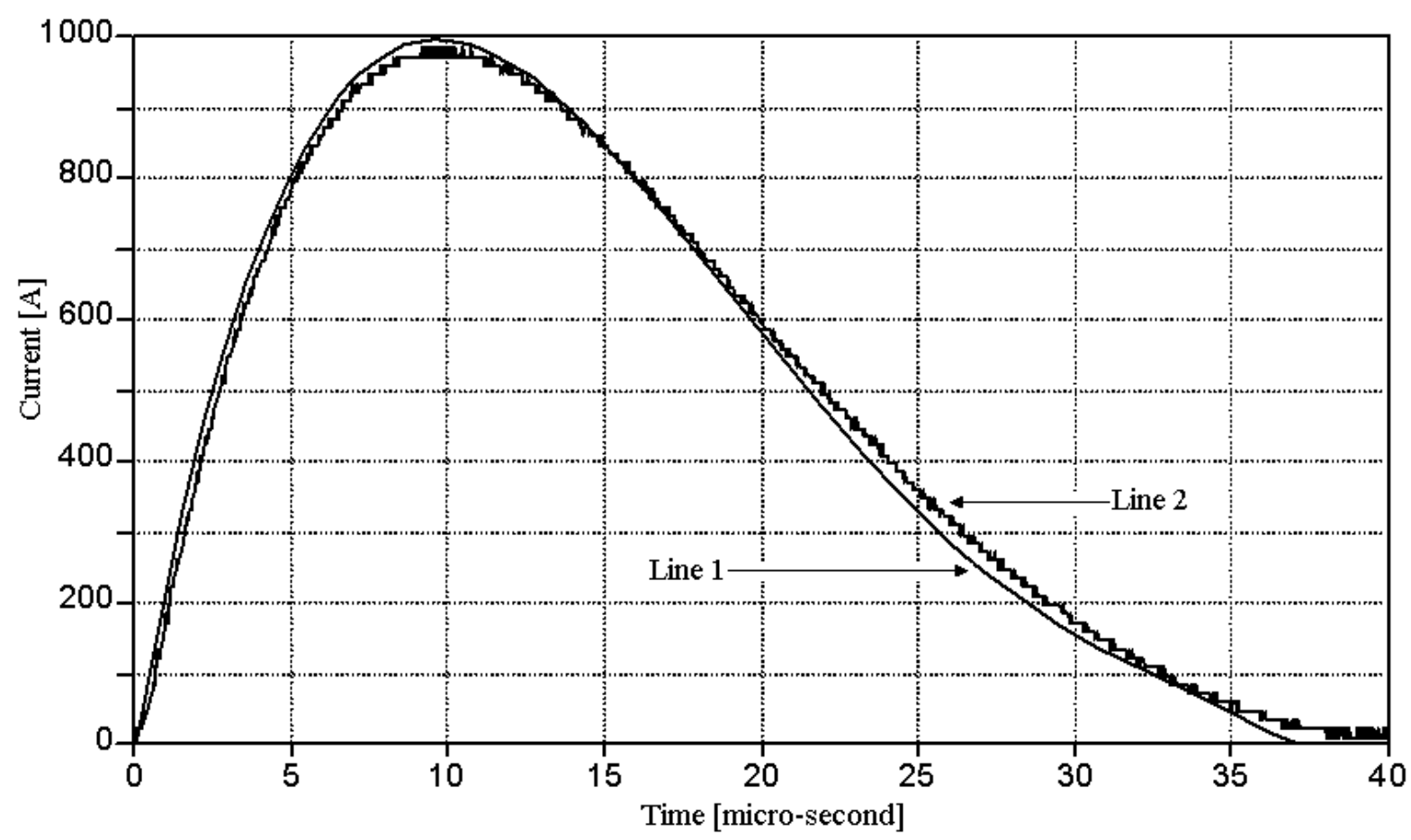

Fig. 5. Standard $8 / 20 \mu$ s lightning impulse (slow front). Line 1: current waveform used in the simulation, Line 2: experimental data.

It can be observed in Fig. 6 that both models give a good agreement with the experimental data. It is important to point out that the fitting of the parameters was made on a trial and error method. Hence, if optimization algorithms were used to characterize the model, better results could be expected [20,21]. However, this is out of the scope of this study.

Fig. 7 \& Fig. 8 shows the residual voltage response for varistors S10K230 and S20K230 respectively. Here it can be observed that, for experimental data, after $35 \mu$ s the residual voltage stabilizes around $340 \mathrm{~V}$, having a very small negative slope. However, if we observed fig. 5, for the current waveform used in the simulation, the current seems to be equal to zero at this time. Therefore to understand this behavior, in the theoretical simulation, for the current waveform used in the simulation, the current was kept constant in around $1 \mathrm{nA}$ after $37 \mu \mathrm{s}$. This allows the simulated results to have a good agreement with the measurement. 
This implies that it is really important to have a proper model of the applied source in order to be able to arrive to the correct conclusions related to the model performance during the simulations.

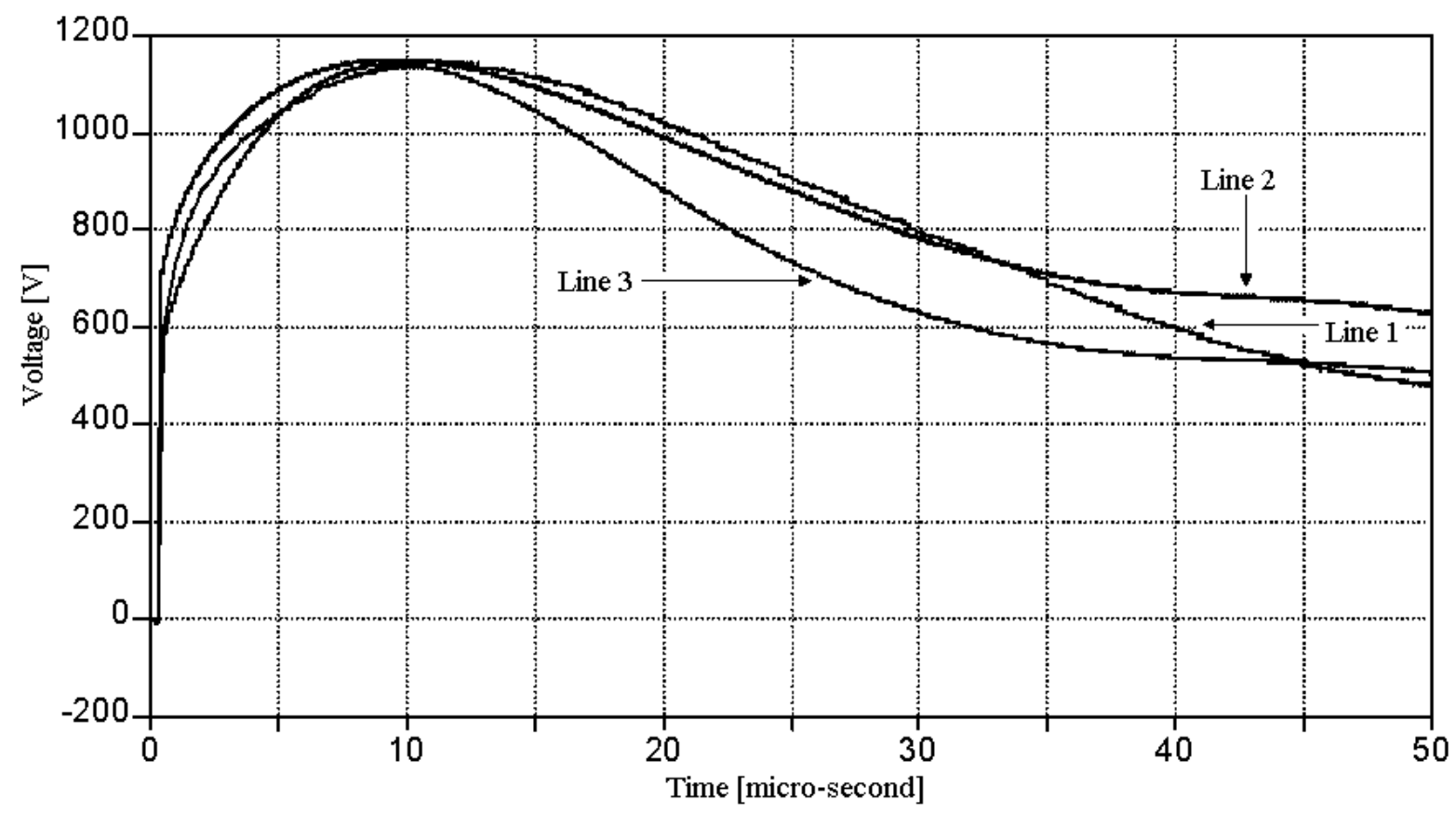

Fig. 6. Residual voltage for varistor S05K230. Line 1: Experimental data, Line 2: Simplified model and Line 3: Durbak's model.

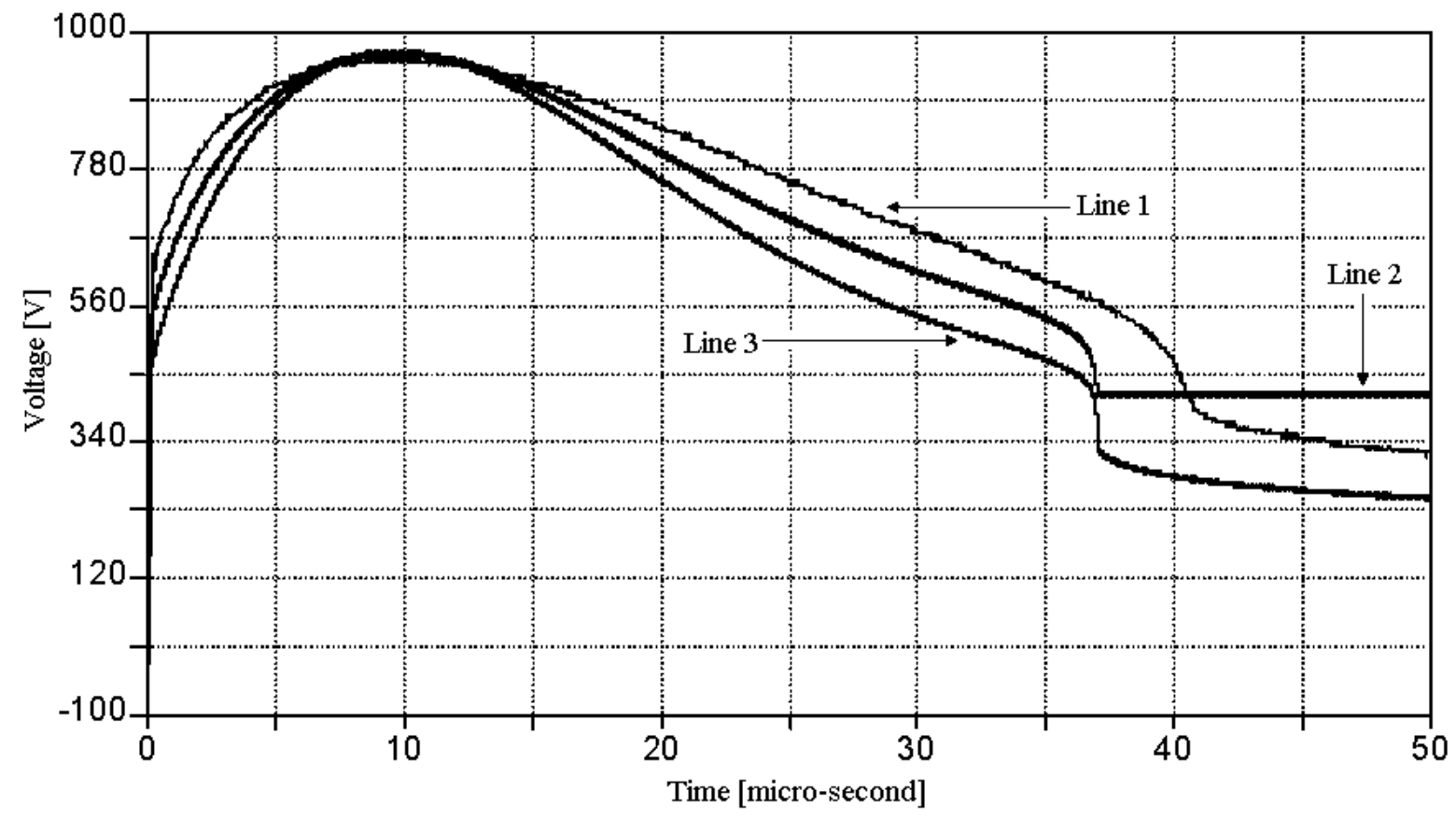

Fig. 7. Residual voltage for varistor S10K230. Line 1: Experimental data, Line 2: Simplified model and Line 3: Durbak's model. 
Also, observe that, when the current reaches the constant value of $1 \mathrm{nA}$, the simplified model keep the voltage constant, while the Durbak's one is capable to reproduce the slow change in the residual voltage. This behavior comes from the interaction of the two nonlinear branches and the inductance $\mathrm{L}_{1}$. Thus, Durbak's model reproduces the slow decaying behavior with a very good agreement.

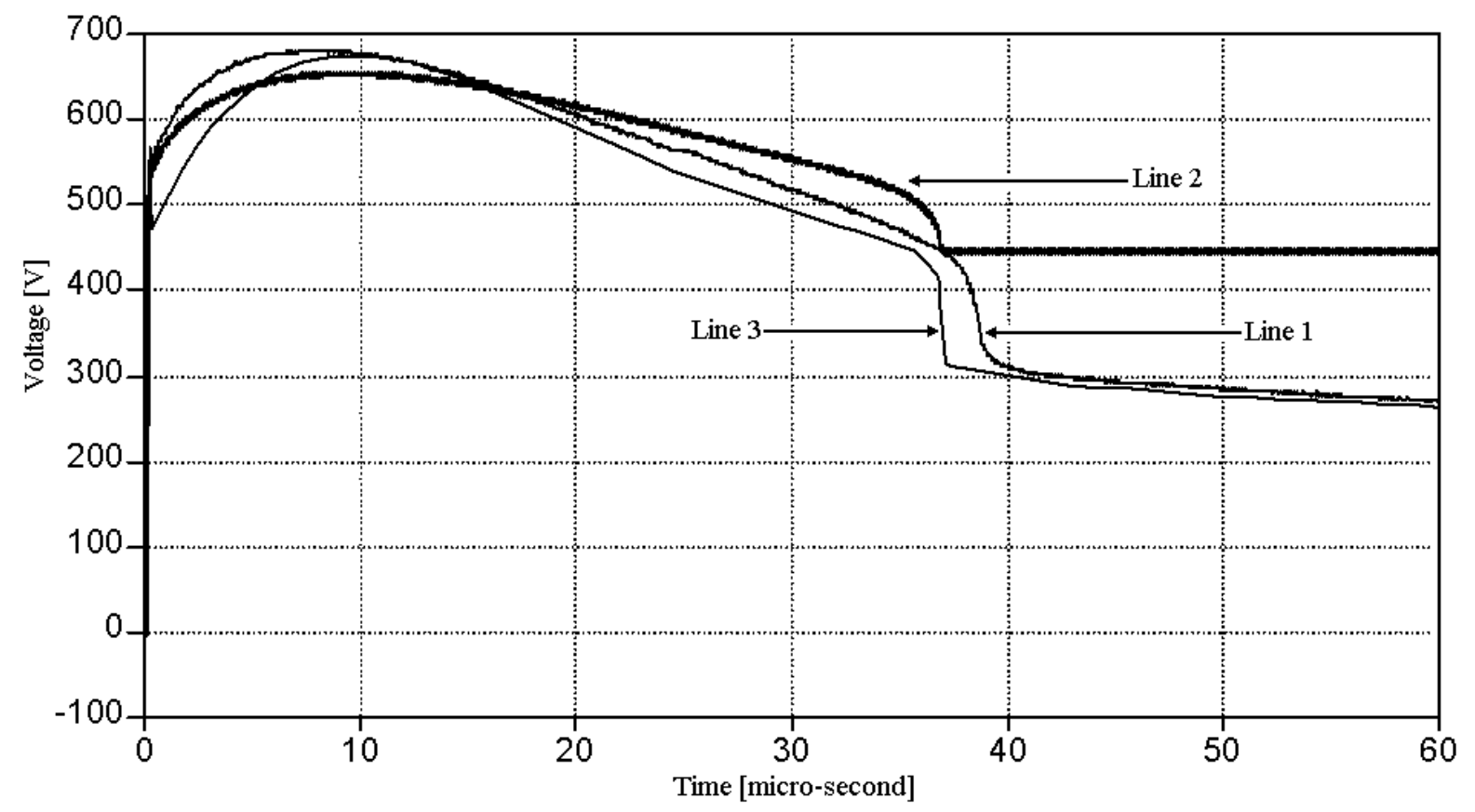

Fig. 8. Residual voltage for varistor S20K230. Line 1: Experimental data, Line 2: Simplified model and Line 3: Durbak's model.

\section{2. Response of varistor models to fast current impulse}

Roman generator is an electrostatic generator capable of delivering a fast current impulse in the sub-nanosecond range as indicated in [5]. Thus, after the identification of the parameters for the different models based on the standard current impulses, a signal similar to the impulse obtained from fast transient generator was applied to the varistor model and resulting voltage drop across its terminal was compared with the experimental data. The fast transient generator was implemented as the RLC equivalent circuit as shown in Fig. 9 as the source for simulations.

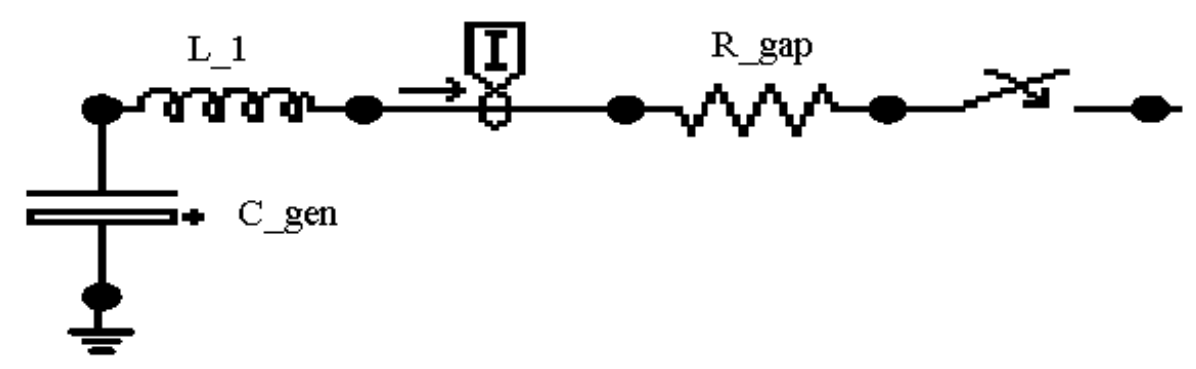

Fig. 9. Equivalent circuit of the Roman Generator. C_gen is the charging capacitor, L_1 is the generator's inductance and R-gap is the discharge channel resistance [15]. 
The voltage response of the varistor S05K230 is presented in Fig. 10. As it can be seen, the peak values obtained by using these two models did not differ considerably. However, simulated results for both models (line $2 \&$ line 3 ) are not similar to the experimental observations (line 1) as shown in Fig. 10. The apparent differences in the peak values as well as the time delay between the varistor models and the measured data could be explained by the voltage drop on the model inductance caused by the high current derivative of the generator.

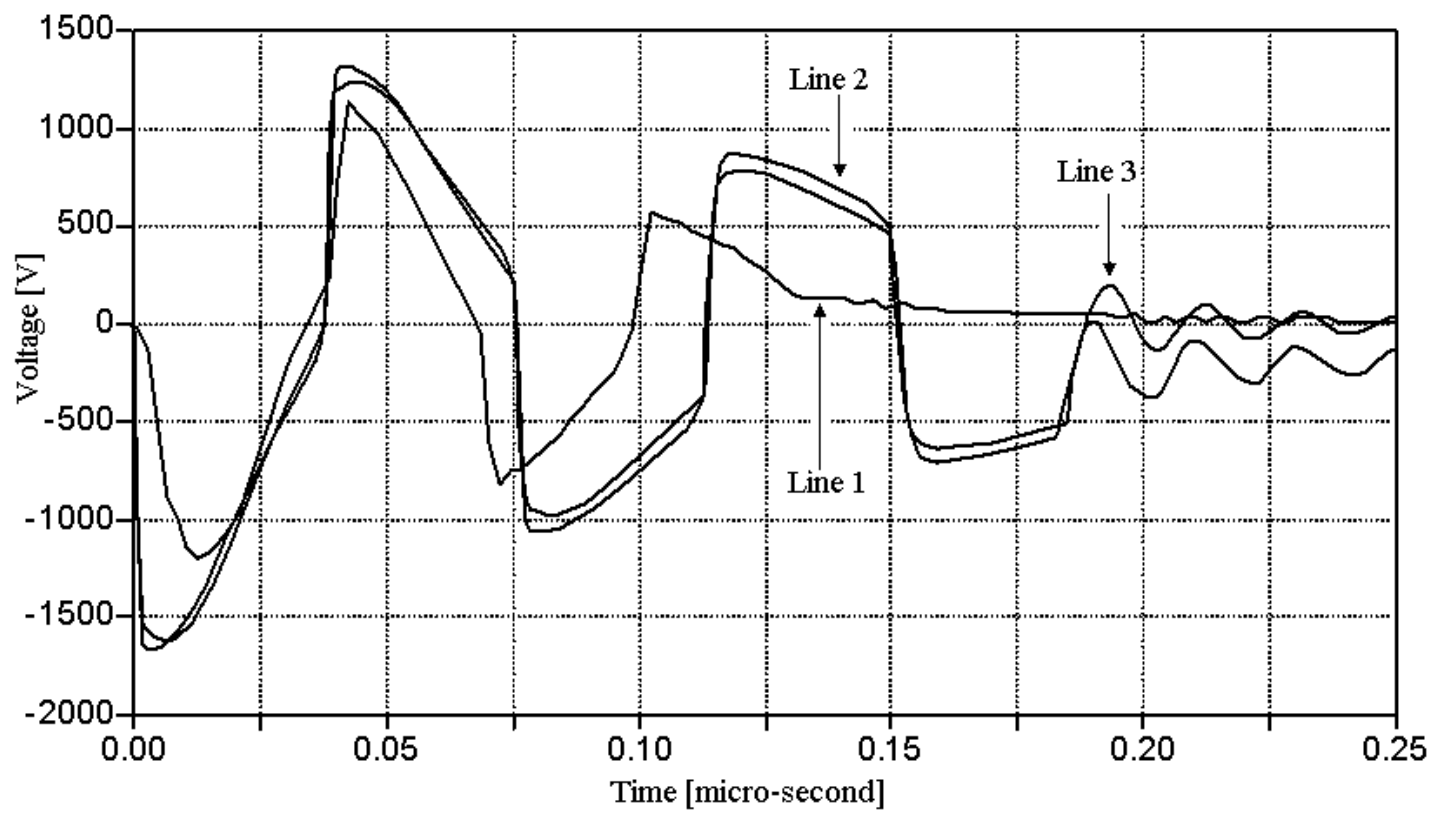

Fig. 10. Residual voltage for varistor S $05 \mathrm{~K} 230$ for a fast front current impulse. Line 1: Experimental data, Line 2: Simplified model and Line 3: Durbak's model.

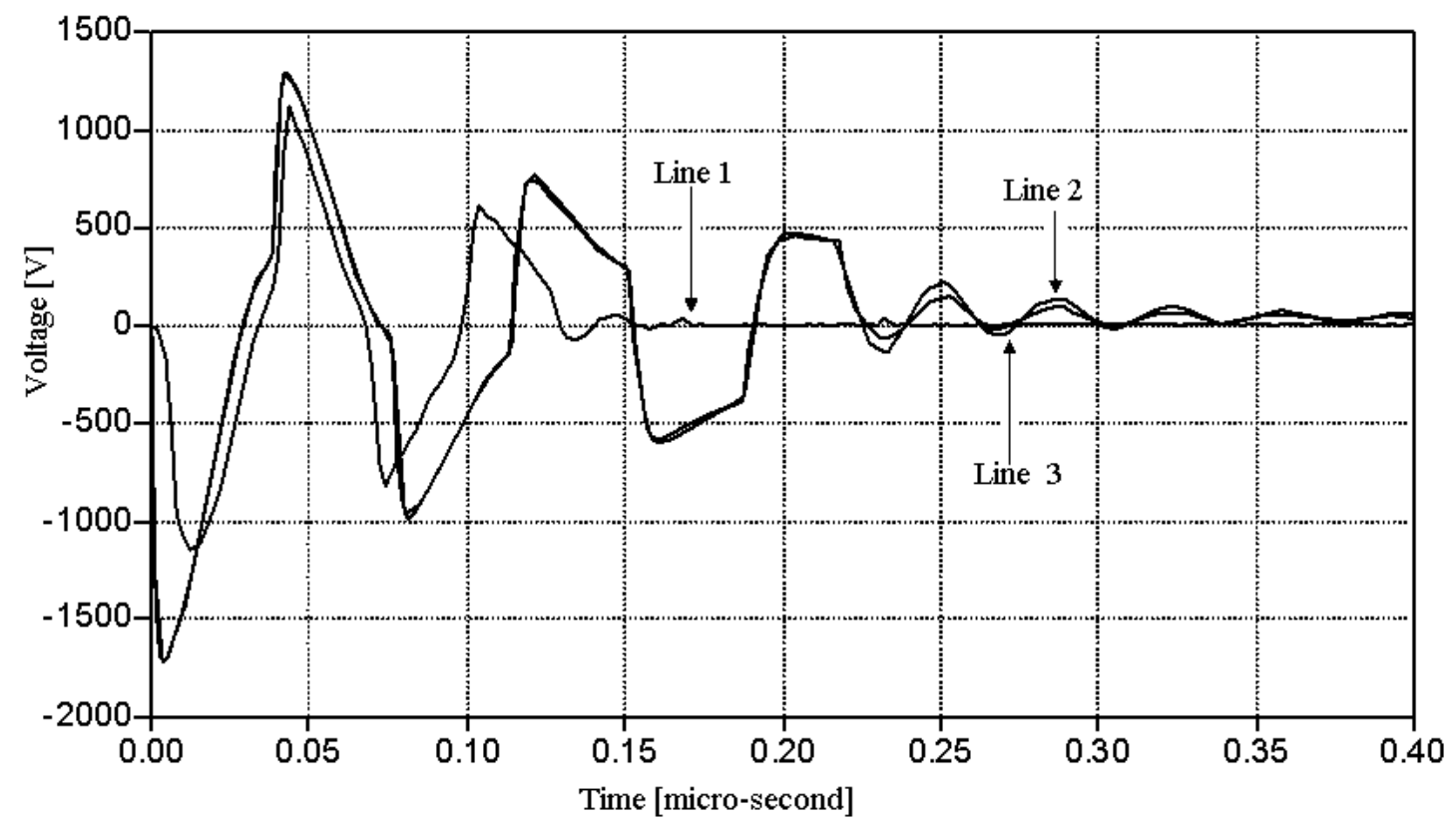

Fig. 11. Residual voltage for varistor $\mathrm{S} 10 \mathrm{~K} 230$ for a fast front current impulse. Line 1: Experimental data, Line 2: Simplified model and Line 3: Durbak's model. 
The voltage response of the varistor S10K230 is presented in Fig. 11. As shown in Fig. 11 , the voltage obtained during the simulation was around $30 \%$ larger than the voltage experimentally measured. Moreover, there were not considerable differences on the voltages obtained with the two different models.

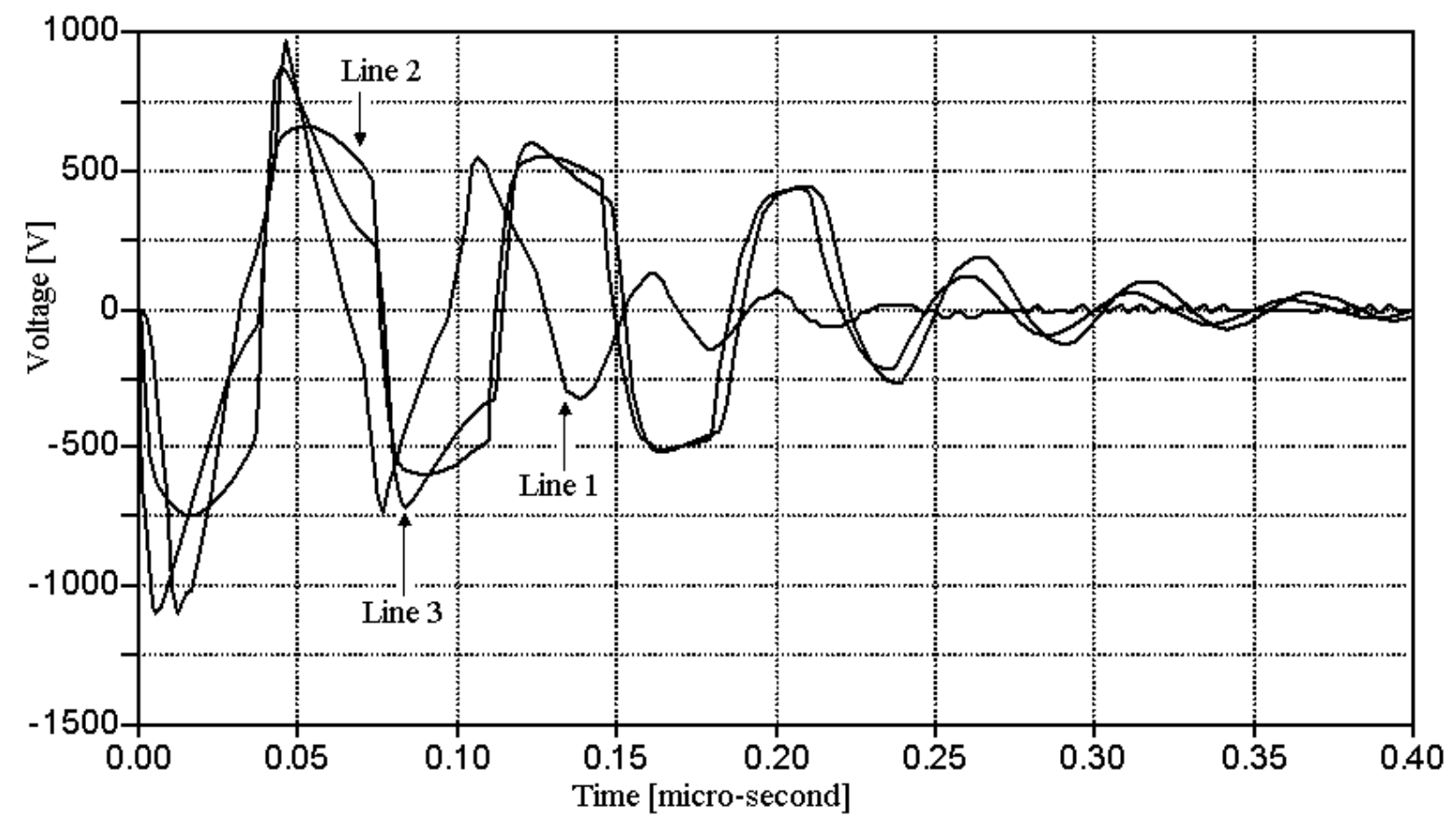

Fig. 12. Residual voltage for varistor $\mathrm{S} 20 \mathrm{~K} 230$ for a fast front current impulse. Line 1: Experimental data, Line 2: Simplified model and Line 3: Durbak's model.

A complete overview of the results is tabulated on Table 2 .

Table 2. Observed results for varistor models to fast current impulse.

\begin{tabular}{|c|c|c|c|c|}
\hline \multicolumn{2}{|c|}{} & \multicolumn{3}{|c|}{ Varistor type } \\
\cline { 3 - 5 } & & S05K230 & S10K230 & S20K230 \\
\hline \multirow{4}{*}{$\begin{array}{c}\text { Clamping } \\
\text { Voltage } \\
(V)\end{array}$} & Experimental data & 1203 & 1140 & 1093 \\
\cline { 2 - 5 } & Simplified model & 1670 & 1740 & 750 \\
\cline { 2 - 5 } & Durbak's model & 1610 & 1740 & 1090 \\
\hline \multirow{3}{*}{$\begin{array}{c}\text { Impulse } \\
\text { Duration } \\
(\text { ns) }\end{array}$} & Experimental data & 235 & 270 & 340 \\
\cline { 2 - 5 } & Simplified model & 250 & 400 & 400 \\
\cline { 2 - 5 } & Durbak's model & 250 & 400 & 400 \\
\hline
\end{tabular}


That is, the branch $\mathrm{A}_{1}$ does not have any influence on the behavior of the varistor model and it is just $\mathrm{A}_{0}$ the one dominating the behavior in this case. The voltage response of the varistor S20K230 is presented in Fig. 12. For the case of varistor S20K230, one can see that the measured voltage peak value is in good agreement with the calculated value with Durbak's model. However, for all the cases as shown in Fig. 10, Fig. 11 \& Fig. 12, the duration of the simulated voltage waveform is larger than the one obtained during the experimental work.

\section{DISCUSSION}

The simulation results were showed that in all the cases for standard current impulses, the models were capable of reproducing the behavior of the varistor with a very good accuracy. However, when the initial portion of the signals is analyzed, it can be seen that there is no perfect match. To illustrate this point, initial part of the residual voltage of varistor S20K230 for a standard current impulse is shown in Fig. 13.

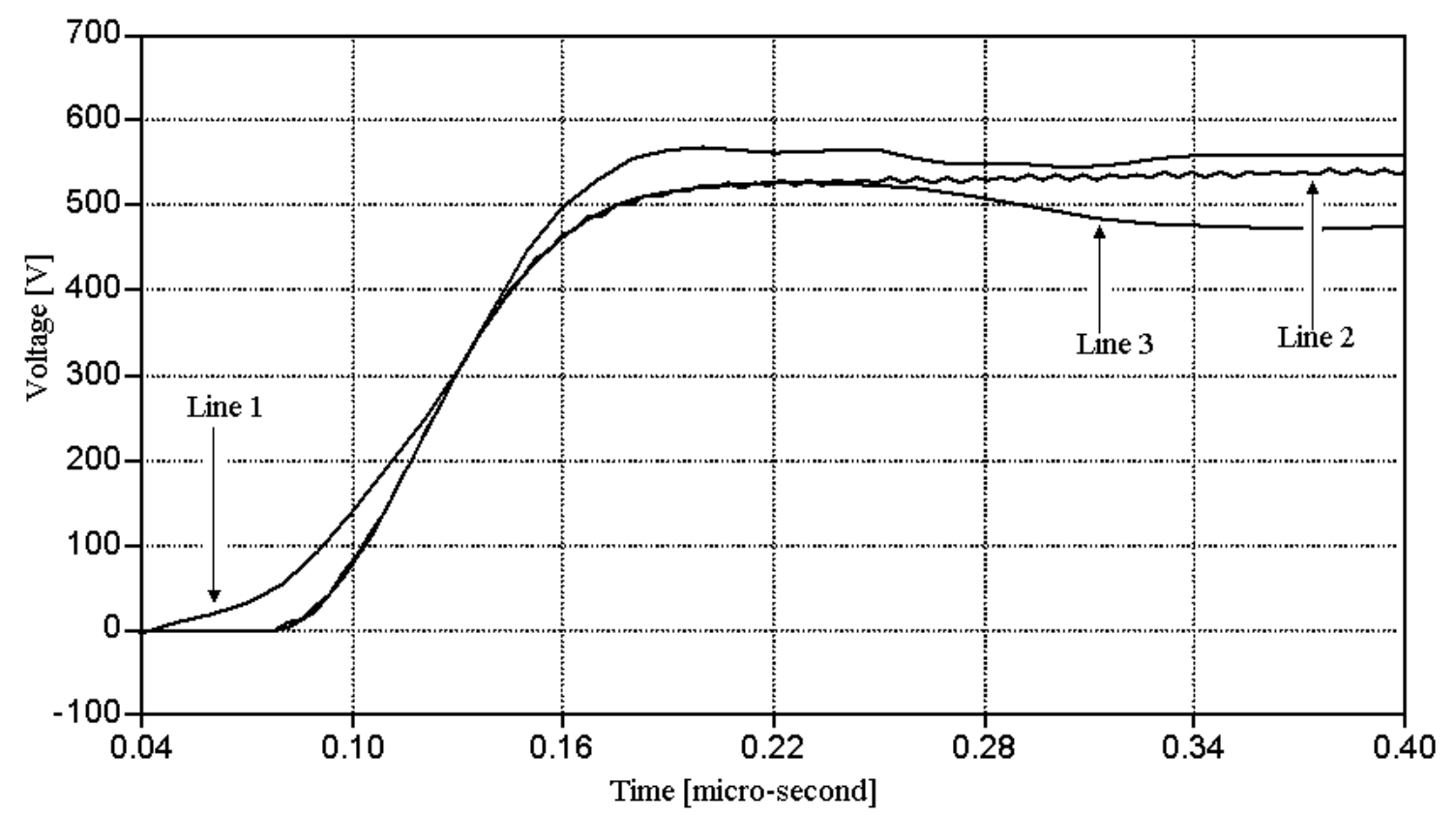

Fig. 13. Initial part of the residual voltage for varistor $S 20 \mathrm{~K} 230$ for a slow front current impulse. Line 1: Experimental data, Line 2: Simplified model and Line 3: Durbak's model.

Note that the slopes of the curves in Fig. 13 were similar. However, the experimental results show a very small slope at the signal initiation which is absent in the simulated one. This difference is due to the numerical model used for the representation of the current wave shape. Hence, to avoid this disagreement, either a better fitting process has to be used or a more detailed model for the source has to be implemented. On the other hand, regardless of the model used for the current source, it can be observed that deviation of the maximum voltage obtained in the first microsecond is less than $6 \%$ of the value obtained during the experiment. 

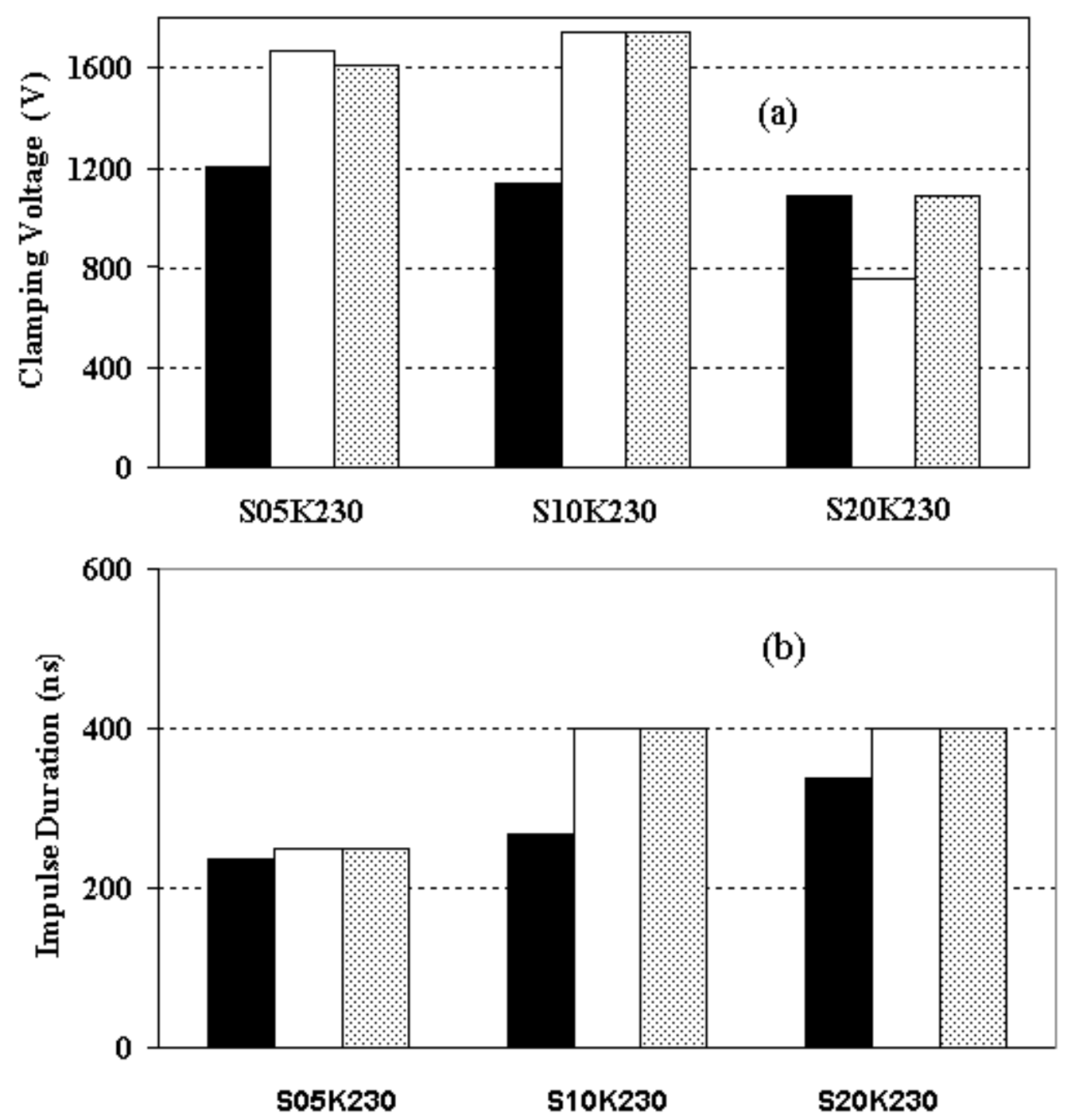

Fig. 14. Observed results for varistor models to fast current impulse:

(a) Clamping voltage. (b) Duration of the simulated voltage waveform.

Black bars: Experimental data, White bars: Simplified model and Bars filled with dots:

Durbak's model.

In the case of the decaying part of the voltage, as it can be seen from Fig. 5, Fig. 6, Fig. 7 \& Fig. 8, the voltage has a slow decay time constant. This is probably caused by the large $\mathrm{RC}$ time constant of the system, $\mathrm{R}$ being the varistor resistance and $\mathrm{C}$ is the capacitance of the generator. However, it has to be pointed out that this type of generators has a gap switch connected in series with the test object. Hence, the potential difference has to be large enough to self-sustain the arc across the gap in order to keep a continuous current path between the capacitance and the test object. In order to reproduce the voltage tail in the simulation, it is necessary to have a current in the order of $1 \mathrm{nA}$ flowing in the varistor. Such a small current are probably generated by the discharge of the charge accumulate on the capacitance of the varistor through its self-resistance. Fig. 14 shows the complete overview for response of varistor models to fast current impulse together with experimental data. 


\section{CONCLUSION}

According to the results obtained, it is very clear that for standard $8 / 20 \mu$ s lightning impulses (slow front currents), simulation results obtained for the models studied had a good agreement with the experimental results. However, it can be concluded with clear evidences that the models need to be improved in order to have a better agreement under high current derivative impulses into the sub-microsecond range.

\section{References}

[1] W. Schimidt, J. Meppelink, B. Britcher, K. Feser, L. Kehl, D. Qiu, IEEE Trans. on Power Delivery 4(1) (1989) 292-300.

[2] M. Zitnik, R. Thottapilli, V. Scuka, “A comparative study of two varistor models", ICLP 2000, Rhodes-Greece 2001.

[3] R. Díaz, F. Fernandez, J. Silva, "Simulation and test on surge arrester in high-voltage laboratory", IPST 2001. Rio de Janeiro Brazil

[4] F. Fernández, R. Díaz, "Metal-oxide surge arrester model for fast transient simulations", IPST 2001. Rio de Janeiro Brazil 2001.

[5] R. Montaño, M. Edirisinghe, V. Cooray, F. Roman, IEEE Transactions on Power Delivery 22(4) (2007) 2185-2190.

[6] Mahesh Edirisinghe, Raul Montaño, Vernon Cooray, "Response of Surge Protection Devices to Fast Current Impulses," $27^{\text {th }}$ International Conference on Lightning Protection - ICLP, France (September 2004).

[7] Mahesh Edirisinghe, Mahendra Fernando, Vernon Cooray, "Performance and withstand capabilities of low voltage varistors under repetitive current impulse environment," International Journal of Engineering and Science Research 2(7) (2012) 2185-2190.

[8] Mahesh Edirisinghe, Velauthampillai Jeyanthiran, Mahendra Fernando, Vernon Cooray, "Performance of Low Voltage Varistors under Repetitive Current Impulse Environment," $28^{\text {th }}$ International Conference on Lightning Protection - ICLP, Japan (September 2006) pp. 784-789.

[9] D. Månsson, M. Becerra, M. Edirisinghe, R. Thottappillil, "Validity of low voltage varistor models when subjected to fast transients," Proceedings of the International Symposium on IEEE National Radio Science Meeting and AMEREM Meeting, Mexico (July 2006), pp. 212.6.

[10] D. Durbak, EMTP News Letter 5(1) (1985).

[11] IEEE Working Group, IEEE Trans. On Power Delivery 7(1) (1992) 302-309.

[12] F. Roman, "Effects of Electric Field Impulses Produced by Electrically Floating Electrodes on the Corona Space Charge generation and on the breakdown voltage of Complex Gaps", PhD Thesis, Uppsala University, Sweden.

[13] F. Roman, "Repetitive and Constant Energy Impulse Current Generator", U.S. Patent Number 5, 923, 130 (Jul. 13, 1999). 
[14] F. Roman, R. Montaño, V. Cooray, "Varistor response under subsequent stoke-like impulse current", Proceeding of $13^{\text {th }}$ International symposium on high voltage engineering, Delft, The Netherlands, August 2003.

[15] R. Montaño, M. Edirisinghe, V. Cooray, F. Roman "Varistor models- a comparison between theory and practice", Proceeding of the $27^{\text {th }}$ International Conference on Lightning Protection, ICLP 2004, Avignon, France. September 2004.

[16] F. D. Martzloff, and K. Phipps, IEEE Transactions On Power Delivery 19(1), (2004) 151-157.

[17] W. Schmidt, J. Meppelink, B. Britcher, K. Feser, L. Kehl, D. Qiu, "IEEE Trans. On Power Delivery 4(1) (1989) 292-300.

[18] Simens \& Matshushita componenta, "SIOV Metal oxide varistor" Pspice model library 1995

[19] R. B. Standler, "Protection of Electronic Circuits from Overvoltages, John Wiley \& Sons, 1989; pp. 87.

[20] M. Becerra, M. Moreno, F. Roman, "Digital parameter identification for metal-oxide surge arrester model”, VIII SIPDA, Curritba-Brazil 2003.

[21] H. J. Li, S. Birlasekaran, S. S. Choi, IEEE Trans. On Power Delivery 17(3) (2002) 736741. 